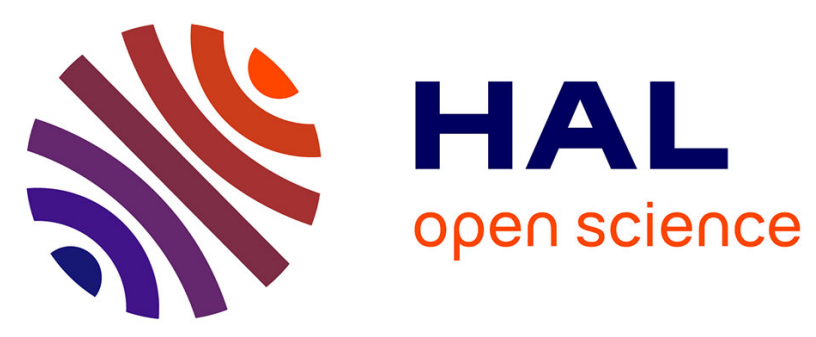

\title{
On the Praxeological Dimension of Organizational Knowledge Conversion: The Example of a "Professionalization Year" for Trainee Teachers in French Agricultural Education
}

Cécile Gardiès, Jean-François Marcel

\section{To cite this version:}

Cécile Gardiès, Jean-François Marcel. On the Praxeological Dimension of Organizational Knowledge Conversion: The Example of a "Professionalization Year" for Trainee Teachers in French Agricultural Education. International Journal of Information Technology and Management, 2013, 12 (3-4), pp.226251. 10.1504/IJITM.2013.054797 . hal-01279221

\section{HAL Id: hal-01279221 \\ https://hal.science/hal-01279221}

Submitted on 9 Mar 2016

HAL is a multi-disciplinary open access archive for the deposit and dissemination of scientific research documents, whether they are published or not. The documents may come from teaching and research institutions in France or abroad, or from public or private research centers.
L'archive ouverte pluridisciplinaire HAL, est destinée au dépôt et à la diffusion de documents scientifiques de niveau recherche, publiés ou non, émanant des établissements d'enseignement et de recherche français ou étrangers, des laboratoires publics ou privés. 


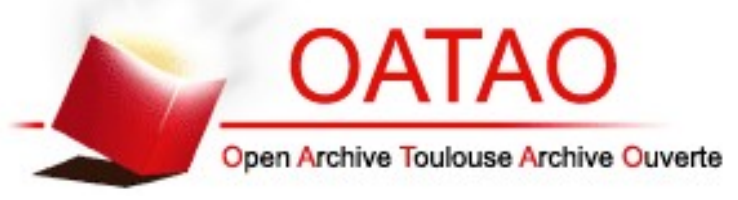

\section{Open Archive Toulouse Archive Ouverte (OATAO)}

OATAO is an open access repository that collects the work of Toulouse researchers and makes it freely available over the web where possible.

This is an author-deposited version published in: http://oatao.univ-toulouse.fr/ Eprints ID: 5654

To cite this version: Gardiès, Cécile and Marcel, Jean-François (2012). On the Praxeological Dimension of Organizational Knowledge Conversion : The Example of a "Professionalization Year" for Trainee Teachers in French Agricultural Education. International Journal of Information Technology and Management (IJITM). ISSN 1461-4111.

Any correspondence concerning this service should be sent to the repository administrator: staff-oatao@inp-toulouse.fr 


\title{
On the Praxeological Dimension of Organizational Knowledge Conversion :
}

The Example of a "Professionalization Year" for Trainee Teachers in French Agricultural

\section{Education}

Cécile Gardiès and Jean-François Marcel

\begin{abstract}
Based on a case study involving changes in teacher education in France, this article proposes to examine knowledge conversion that is altered by new social practices, leading to socioepistemic breaks. Hence, other knowledge conversion dynamics become established, enabling a questioning of the initial theoretical models. The text points out the emergence of a third axis in the model under study and permits consideration of the conversion process by integrating a knowledge (epistemological axis) that is embodied and mobilized (ontopraxeological plane), an action (praxeological axis) that is embodied and elucidated (ontoepistemological plane), and a knower (ontological axis) that knows and acts (epistemopraxeological axis).
\end{abstract}

\section{Introduction}

Models for the sharing and diffusion of knowledge within organizations have developed notably based on economic or entrepreneurial contexts. They enable analysis of the way organizational knowledge is constructed and transformed, as well as how it is involved in individual, but also collective, performance. These models can also be at work in the frame of an organization devoted to training, especially since knowledge creation is central to the dynamic of such an organization. This text is thus based on a case study touching on teacher education in the French agricultural education system.

This case study will enable us to mobilize the conceptual frame of organizational knowledge conversion developed in the field of knowledge management, as well as to test it and to propose further developments. Our text will describe the model and its recent developments, then present the methodology and results of a study led with the actors involved in a professionalization year for teachers. Finally, based on the analysis of results, the paper will identify the limits of the model for the case study examined and will propose a contribution to the evolution of the model.

\section{Problematization}

The French mastérisation reform implemented in 2010 has substantially influenced teacher education in the country. When it comes to public agricultural education, successful competition candidates are directly appointed to an establishment position with a partially reduced teaching load (2/3 of the regular teaching workload). At the request of the responsible ministry, and in line with its national mission, the École Nationale de Formation Agronomique or ENFA was put in charge of this year of alternating training, titled année de professionnalisation or "professionalization year," using a specific structure or "device" consisting of three main components:

- training sessions that bring together trainee teachers and are hosted by ENFA trainers;

- training in an assigned establishment (supervised by "pedagogical counselors," experienced peers, with the contribution of management teams); and 
- a method for distance monitoring using a collaborative platform, permitting interrelations between trainee teachers and the various training referents (ENFA and establishment).

The professionalization year was established to allow trainee teachers to develop the professional competencies required to practice their profession. However, changes in teacher education and its new methods involve various actors in a new model of knowledge sharing and diffusion, in a device in which knowledge creation is central to the organizational dynamic. When the organizational dynamic undergoes change, the conversion of knowledge is altered, notably because of new social practices that impact motivations and human interaction models and yield socio-epistemic breaks.

In this new organization, other dynamics of knowledge conversion become established and mobilize spatio-temporal and inter-relational forms that remain to be described and explained. The aim of the present text is to question the learning function in this organization, in the sense that it takes part in the construction, diffusion, and transformation of knowledge. What knowledge is created and put into circulation in this organization, and consistent with what individual and collective dynamic? How is knowledge shared within an organization that engages actors through distance measures? What are the resulting transformations in the management and sharing of knowledge? How is this knowledge appropriated?

In the frame of the organization here studied (professionalization year for trainee teachers in French agricultural education), the knowledge involved has to do with a professional and practical epistemology relative to the teacher's work. The intent of this article is to explore the modes of knowledge construction, circulation, and diffusion and the ways it is appropriated, particularly in line with the nature of this knowledge and the way it is shared (training session, pedagogical counselor, distance monitoring, exchanges between trainee teachers, virtual and face-to-face sharing of experiences, collaborations in the context of professional practice, etc.) in order to ascertain whether organizational knowledge that addresses "break" situations is created and whether it plays a part in the training of actors. This is done by attempting to measure the factors that impact the performance of these actors (Nonaka, Krogh, 2009) all while remaining attentive to the way this knowledge is shared in a community.

\section{1- On the conversion of organizational knowledge}

Unlike other models such as cognitive models of knowledge acquisition, theories in knowledge management have developed knowledge conversion or creation models based on a dynamic (spiral) process between tacit and explicit knowledge involving both epistemological and ontological dimensions. Among other things, these models have studied modes of knowledge conversion within businesses (Nonaka, 1994). Like certain French authors (Astolfi, Jeanneret), they have nevertheless been unable to escape the difficulty of differentiating information, connaissance, and savoir, even if in the English-speaking world the word "knowledge" encompasses both connaissances and savoir. We have nonetheless noted a distinction made between information, explicit knowledge, and tacit knowledge (Nonaka, Krogh, 2009), which relates to the distinction found in the French terms. The role of information is, however, often neglected in models in favor of a focus on that of knowledge (Baumard, 1996). Researchers in the field have recently brought to light questions that had not yet been addressed in the description of the dominant models in KM, notably the nature of knowledge and its role in social entities. In other words, these researchers have underscored the need to draw on other scientific approaches to better define knowledge (philosophy), to approach its role in businesses by calling on economic and/or sociological approaches, and to explain human interaction motivations and models via psychology by considering more 
subjective perspectives; thus, "Organizational knowledge creation is the synthesis of subjectivity and objectivity" (Nonaka, Peltorkopi, 2006). Researchers have additionally pointed out that the conversion or creation of knowledge in a community (social entity) can always be approached by distinguishing tacit knowledge from explicit knowledge, but henceforth is conceived only along a continuum (Nonaka, Krogh, 2009) and taking into account its intersections with the social practices seen as necessary but insufficient in the process of creating organizational knowledge. Various actors indeed validate their tacit knowledge through social interactions. Subjective knowledge is thus objectivized and becomes a real and socially justified belief. "Organizational knowledge creation means that subjective tacit knowledge held by an individual is externalized into objective explicit knowledge to be shared and synthesized" (Nonaka, Peltorkopi, 2006). As a result, these processes remain particularly interesting to study in their complexity in view of establishing links between the creation of this organizational knowledge and social practices to elucidate the training of different actors and to understand the factors that influence their performance (Nonaka, Krogh, 2009) and professionalization, namely by concentrating on the way this knowledge is shared within a community.

\section{dimension) \\ 1-1 Organizational knowledge and the nature of knowledge (epistemological} Organizational knowledge can be defined as the sum of pooled knowledge with regard to which actors can exercise a meaningful approach and that takes on significance in its application, that is to say it comes under a dynamic of use, transmission, and appropriation. Organizational knowledge creation is a process that hinges on the will of actors to find meaning in the information presented to them and it is thus based on the communication of meaning. Instruments for managing organizational knowledge can permit regulation and management of relational modes between actors in a given environment where knowledge finds its raison d'être, it meets economic requirements (for example answering needs, completing tasks, undertaking new tasks) but also psychological ones (for instance managing uncertainty or change). Because it is based on a pooling of individual knowledge (one could say a socialization of knowledge), however, the creation or conversion of organizational knowledge presupposes an understanding of the nature of the knowledge in play to be able to approach such processes.

The dynamic of knowledge is based on information in circulation, which leads us to distinguish between the notions of information and knowledge. P. Baumard, in parallel with a number of authors in the area of information and communication sciences (ICS) according to whom these terms "commonly understood as interchangeable" (Baumard, 1996) ${ }^{1}$ are in fact quite distinct, defines information as "a flow of messages that increase knowledge, restructuring it and changing it; a raw material that generates knowledge" (Baumard, 1996). In ICS this definition goes further by distinguishing information and connaissance from the notion of savoir; information is defined as "communicated or communicable knowledge" (Meyriat, 1983). It should nevertheless be specified that information has a communicational value and becomes knowledge only when activated by an individual who receives it in an exchange, who integrates and assimilates it into his/her own stock of knowledge. "We propose to use the term . . connaissance to indicate the productive work that subjects do on themselves to appropriate ideas or methods, and that of savoir to describe forms of knowledge recognized by a society" (Jeanneret, 2000). Losfeld highlights the importance of the individualization of knowledge, since "knowledge [connaissance] can only be based on what

1 All translations from French in the text are ours. 
has previously been done or said, whether it is integrated or rejected . . all knowledge, because it rests on the consideration of previous 'documents,' their reading and exploitation, is individualized" (Losfeld, 1990). Knowledge therefore takes on a personal and subjective nature, while according to Foucault, knowledge [savoir] can be defined as "this set of elements, formed regularly through discursive practice and indispensable to the constitution of a science-even though it may not give rise to it - that can be called savoir" (Foucault, 1975). In the words of Deleuze, savoir can be summarized as "the ordering of what an era can say (its statements) and see (its perceived facts)" (Deleuze, 1986).

Citing various authors, Nonaka and Poltokorpi (2006) also distinguish between "knowledgethat" and "knowledge-how" (practical knowledge) by making links between all these different categorizations, for example by making a parallel between tacit knowledge that is difficult to articulate and transmit, to be transmitted with "know-how," and explicit knowledge that is relatively easy to articulate and codify, tied to declarative knowledge. In their view, these categories show that knowledge has both objective and subjective dimensions that are complementary rather than exclusive.

This differentiation being established, we can now set down the distinction between tacit and explicit knowledge as proposed in the field of knowledge management, and which provides a way to approach the very notion of organizational knowledge by specifying the nature of this knowledge.

Tacit knowledge thus has to do with abilities, the intuition of implicit rules and know-how, and is subjective; in contrast, explicit knowledge is universal in character, objectivized. "The concept of 'tacit knowledge' is a cornerstone in organizational knowledge creation theory and covers knowledge that is unarticulated and tied to the senses, movement skills, physical experiences, intuition, or implicit rules of thumb. . . . Tacit knowledge differs from 'explicit knowledge' that is uttered and captured in drawings and writing. . . Explicit knowledge has a universal character" (Nonaka, Krogh, 2009).

In our view, the difference between tacit and explicit knowledge runs parallel to the French distinction between connaissance and savoir, which in no way precludes complementarity between the two, even their placement along a continuum, implying a back-and-forth movement. Hence "the concept of knowledge conversion explains how tacit and explicit knowledge interact along a continuum" (Nonaka, Krogh, 2009). The explicitation of knowledge in view of sharing it thus becomes transmitted information that allows the diffusion of this knowledge and its appropriation by another individual, and thereby the constitution of new knowledge. "Knowledge tied to the senses, tactile experiences, movement skills, intuition, unarticulated mental models, or implicit rules of thumb is 'tacit.' Tacit knowledge is rooted in action, procedures, routines, commitments, ideals, values, and emotions. Tacit knowledge can be accessible through consciousness if it leans towards the explicit side of the continuum. . . . The notion of 'continuum' refers to knowledge ranging from tacit to explicit and vice versa. By incorporating 'tacit knowledge,' organizational knowledge creation theory overcame mainstream theory's tendency to equate knowledge with information" (Nonaka, Krogh, 2009).

To be shared, tacit knowledge undergoes transformation into explicit knowledge, which does not automatically imply collective knowledge since "there may well be collective knowledge without there being any unilateral mechanism of cognition, interpretation, and attribution of meaning. This is the difference between collective knowledge and collective cognition. The fact that there exists collective knowledge in no way implies the homogeneity of this knowledge. It can be completely heterogeneous, but still belong to the community" (Baumard, 
1996). The question now arises: What are the possible forms of knowledge sharing, and in view of what transformation?

\section{(ontological dimension) \\ 1-2- The subject, the group, and the transformation of knowledge}

All knowledge, though it takes on a personal character, is anchored in a social context and specific time, and in this sense it can be said that it is in part socially constructed. It contributes to individual but also collective performance; one could say that organizational knowledge is created in a process and implies specific management. "Organizational knowledge creation is the process of making available and amplifying knowledge created by individuals as well as crystallizing and connecting it to an organization's knowledge system" (Nonaka, Krogh, 2009: 635). Indeed, as Nonaka and Peltokorpi have underlined, actors validate their tacit knowledge through social interactions, and subjective knowledge is thusly objectivized and can be shared. Organizational knowledge can consequently be viewed as a synthesis between subjectivity and objectivity. "[T]o complement the knowledge-based view of the firm and the theory of dynamic capabilities by explaining the dynamic processes of organizational knowledge creation . . . two premises were important in this effort : tacit and explicit knowledge can be conceptually distinguished along a continuum, and knowledge conversion explains the interaction between tacit and explicit knowledge" (Nonaka, Krogh, 2009: 636).

The model of organizational knowledge creation developed by Nonaka (1994) primarily focuses on the sense of information in its semantic aspect, that is, it "literally means that it contains new meaning." It also rests on the postulate of the importance of knowledge and its management within a social organization. He identifies an ontological dimension, that is, several levels of social interaction, as no organization can produce knowledge without individuals; the creation of organizational knowledge can be understood in the sense of an amplification of personal knowledge that is networked, shared. Nonaka highlights three essential factors that induce individual commitment within an organization: intention, autonomy, and environmental fluctuation. Intention refers to the way individuals approach the world and attempt to create meaning and to adapt to their environment. Without intention, it is impossible to evaluate information. The principle of autonomy can be applied to the individual, the group, and the various levels of organization, separately or together. Each individual has a personality and if the organization permits autonomous behavior, this encourages the acquisition of new knowledge, and autonomy provides individual freedom for appropriating knowledge. Fluctuation stresses the importance of interaction between the subject and the environment. The model of the knowledge spiral enables a grouping of the ontological dimension described above with the epistemological dimension by identifying four modes of interaction between tacit knowledge and explicit knowledge. These modes represent the way existing knowledge can be transformed into new knowledge. Social interactions between individuals provide the ontological dimension of increasing knowledge. These four modes of knowledge transformation are from tacit knowledge to tacit knowledge (experience, imitation, mentorship, socialization); from explicit knowledge to explicit knowledge (exchanges, categorization, reconfiguration of information, combination); from tacit knowledge to explicit knowledge (complementarity of knowledge, expansion of knowledge through interactions, externalization); and from explicit knowledge to tacit knowledge (action, learning, teaching, internalization). "The coherence and consistency of organizational knowledge reside in the dynamics of its transformation. . . Hence explicit and shared elements of knowledge can progressively 'crystallize' around the tacit emergence of 
collective needs" (Baumard, 1996). Processes of organizational knowledge creation are never "finished" but rather involve a circular process that is in fact not limited to the organization but includes many interfaces with the environment (Nonaka, 1994). This model, though it still appears to be relevant for approaching the process of creating or transforming organizational knowledge-and hence for understanding the construction of knowledge within an organization- has become enriched as the search for other elements has progressed. We will discuss two, that of taking into account social practices, since "organizational knowledge creation is very sensitive to social context" (Nonaka, Krogh, 2009), and that of the objectivity-subjectivity continuum between tacit and explicit knowledge, even if "social practices may be necessary, but not sufficient, for understanding organizational knowledge creation" (Nonaka, Krogh, 2009). For the purposes of this article, we will set aside the question of the results of knowledge transformation, which is not often addressed in the initial models.

\section{1-3- Organizational knowledge and social practices (praxeological dimension)}

"A social practice brings routine and stability to behavior and processes. Thus, we propose that social practices may evolve around knowledge conversion, there may exist a coherent, complex, coordinated form of human activity in the shape of socialization, combination, externalization and internalization. . . . knowledge conversion may have both a knowledge and a social practice outcome. More research is needed on the emergence of new social practices of knowledge conversion" (Nonaka, Krogh, 2009).

The tacit knowledge of practitioners often acquired in diverse social practices is a source of creativity and is constitutive of innovation and organizational culture. "[O]rganizational culture is primarily a tacit system of knowledge transformation and regulation . . . the passage from tacit knowledge to explicit knowledge (articulation) and from the explicit to the tacit (internalization) are the twin engines of organizational learning" (Baumard, 1996).

The sharing of information within an organization can enable the transcending of knowledge as much as that acquired in social practices. Nonaka advances that "tacit knowledge is constitutive of social practice" (Nonaka, Krogh, 2009).

It is the interaction between actors that is here central to the process and that touches on the conception of information in circulation as "the cognitive content of potential or realized communication" (Meyriat, 1983), that is, information within an organization will find its meaning only when it is shared (implying a social practice) and upon activation once it is received. This will trigger a process of signification and hence of knowledge construction for the individual. Hence "interactions constitute the fabric of social practices" (Nonaka, Krogh, 2009). It is nevertheless important not to neglect the structures that support the creation and transformation of organizational knowledge-we refer to them as "devices"-as these are not "simply a technical system and a tool serving a project . . . but constitute the point of departure for new forms of collective organization" (Hert, 1999), notably infocommunicational devices understood as "social and technical dimensions . . . devoted to the pooling of information to be activated, [which] would thus be made up of actors, techniques, and material objects in permanent interaction in a defined context, linked by a network" (Couzinet, 2008).

It is indispensable to take into account the dynamic between individuals and communities, since in an organization it is within this whole of discourse, learning, but also background (by which Anglo Saxon authors refer to Bourdieu's notion of habitus) that are structured the identities which have an important symbolic role to play in the construction of organizational knowledge. "The instrumental rationality of the device belongs to an organizational logic 
specific to the technique of the occupations on which it depends, norms and know-how, and the habitus of its actors" (Couzinet, 2008).

Knowledge and the signification process can be seen as socially constructed and cannot be reduced to the transmission of meaning by subjects taken individually. This approach of social and collective knowledge creation rests on the dominance of constructive social interactions. It is also possible to consider the process of organizational knowledge creation as one in which individual knowledge is amplified and internalized as a fundamental part of organizational knowledge and vice versa (Nonaka, Peltokorpi, 2006).

While this interaction between social practices and organizational knowledge creation has recently been acknowledged as a very important one to take into account in knowledge management theories, its link with training and competencies (in other words the connections between knowledge and performance) remains largely unexplored, as Nonaka and Krogh point out: "[F]uture research on the relationship between organizational knowledge creation and social practice should account for team formation and factors that impact on team performance" (Nonaka, Krogh, 2009). This is precisely the subject of our empirical investigation presented below.

In the Nonaka model there is a significant connection between the subjects (individuals but also groups or institutions) and the different social interactions. We propose to untangle these two aspects using a model with three clearly identified dimensions: the epistemological dimension concerning the nature of knowledge, the ontological dimension regarding the knower, and the praxeological dimension relating to social action, interactions, and practices.

\section{Methodology}

An examination of the knowledge conversion dynamics within a given organization first requires some specification of the nature of this knowledge.

\section{1 - On the nature of the knowledge studied}

In the context of our study, it appears necessary to specify the nature of knowledge in the organization by crossing its level of explicitation with its finalization, in line with the mastery of the professional practice targeted by the organization. To do so, following Osty (2003) we have distinguished two categories of "professional knowledge" here understood in its broader sense, that is, knowledge mobilized by teachers in the frame of their professional practice to undertake the tasks with which they are entrusted (Marcel, 2009). This includes professional knowledge relative to undertaking professional tasks (knowledge that permits teachers to "carry out" their profession) on the one hand, and professional knowledge relating to professional socialization (knowledge that enables teachers to "be in" their profession). This crossing leads us to suggest four knowledge types, presented in the table below:

\begin{tabular}{|l|l|c|c|}
\hline \multirow{2}{*}{$\begin{array}{l}\text { Knowledge "with professional } \\
\text { aims" }\end{array}$} & \multicolumn{2}{|c|}{ Finalization } \\
\cline { 3 - 4 } & $\begin{array}{l}\text { Knowledge relative to } \\
\text { undertaking professional } \\
\text { tasks }\end{array}$ & $\begin{array}{l}\text { Knowledge relative to } \\
\text { professional socialization }\end{array}$ \\
\hline \multirow{2}{*}{ Nature } & Tacit knowledge & Type A & Type B \\
\cline { 2 - 4 } & Explicit knowledge & Type C & Type D \\
\hline
\end{tabular}


We used a questionnaire survey administered to all 69 trainee teachers involved in the professionalization year.

The questionnaire underwent prerequisite test phases. It enabled exploration of the following:

- the uses of various devices and modes of knowledge sharing;

- the "results" of the knowledge conversion; and

- the identification and description, by these actors, of the processes proposed by Nonaka.

The response rate proved to be fairly satisfactory at $49.3 \%$.

The survey was also supplemented:

- with an analysis of reference texts and meeting minutes to objectivize the "input" of information within the organization;

- with a gathering of "traces" of exchanges through transcripts from the collaborative platform.

Aside from the inputs component that drew on a rather qualitative approach, the treatment of the survey and transcripts used statistics, essentially descriptive in fact.

\section{3 - Description of study results}

The description will be presented chronologically. It will begin with the information inputs within the organization, follow with the dynamics of knowledge conversion (through the modes of knowledge sharing), and end with the result, at the "output" of the organization. These results will allow us to propose an initial modeling of organizational knowledge conversion.

\section{1 - The various information inputs in the organization}

Analysis of information inputs in the studied organization reveals two differentiation modes. The first concerns the nature of these inputs, more precisely the prerequisite operations to which they are submitted before being diffused in the system. The second has to do with the conditions of their diffusion, and information varies depending on both the space in which it comes into play and the social interactions at work in its diffusion.

\subsection{1 - Two prerequisite operations}

Before becoming information that will be diffused within the organization, knowledge undergoes epistemological transformations directly related to its initial nature. Thus explicit knowledge relative to undertaking professional tasks (type $\mathrm{C}$ : teaching content, classroom management, learning theories, etc.) or regarding professional socialization (type D: code of ethics, definition of statutes, areas of authority of establishment structures, etc.) is academic knowledge. It is consistent, structured, explicit, known and acknowledged, public, etc. Its transformation into information will require an epistemological operation (operation 1) of a "didacticizing" nature, that is, the adaptation of knowledge to modes of diffusion (course, platform, etc.) and to addressees.

It should be noted that the system will see the introduction of information stemming from the transformation of tacit knowledge (of type A or type B), that is, intuitive, largely tacit, and requiring structuring into a message in order to reach the status of information, which we have described as "verbalization" understood as a minimal setting to words. Therefore, as the following table shows, at the entry to the system we have two types of information, namely didacticized information and verbalized information:

\begin{tabular}{|l|l|l|l|l|}
\hline $\begin{array}{l}\text { Operation 1 } \\
\text { "didacticization" }\end{array}$ & $\begin{array}{l}\text { Explicit knowledge, } \\
\text { type C or D }\end{array}$ & $\begin{array}{l}\text { Epistemological } \\
\text { transformation }\end{array}$ & $\begin{array}{l}\text { "Didacticized" } \\
\text { information }\end{array}$ & $\begin{array}{l}\text { Diffusion } \\
\text { (input) }\end{array}$ \\
\hline
\end{tabular}




\begin{tabular}{|l|l|l|l|l|}
\hline $\begin{array}{l}\text { Operation 2 } \\
\text { "verbalization" }\end{array}$ & $\begin{array}{l}\text { Tacit knowledge, } \\
\text { type A or B }\end{array}$ & $\begin{array}{l}\text { Epistemological } \\
\text { transformation }\end{array}$ & $\begin{array}{l}\text { "Verbalized" } \\
\text { information }\end{array}$ & $\begin{array}{l}\text { Diffusion } \\
\text { (input) }\end{array}$ \\
\hline
\end{tabular}

\subsubsection{Different information according to the conditions of diffusion}

A second level of differentiation of information appears according to the conditions of its diffusion. We will examine the three devices that make up the studied organization.

\section{- The "ENFA Groups" device}

Three areas of diffusion must be distinguished:

- Training sessions: they involve a relatively traditional form of teaching even if the modes of trainee teacher groups vary substantially (but are always collective). They are formalized and circumscribed in the space-time of the schedule and classrooms. They favor the diffusion of didacticized information and, even if they mobilize written or audiovisual media, their chief medium is oral communication.

- Trainer / trainee teacher meetings: not very formalized (exception made for appointments), they are situated outside of schedules and classrooms. These meetings favor an inter-individual mode (sometimes a very small group) and, even if they come within a context characterized by didacticized information, they largely emphasize verbalized information. Their medium is, here again, oral communication.

- Exchanges between trainee teachers: these concern all that touches on "community life" during several weeks in a training school. These exchanges, very much marked by a convivial if not fraternal dimension, use only verbalized information, a little bit of type A, a lot of type B, and exclusively call on the mode of oral communication.

\section{- The "establishment-based training" device}

Two modes must be distinguished here:

- Pedagogical counseling which takes the form of an interview (a debriefing), most often following a session piloted, depending on the case, by the pedagogical counselor or the trainee teacher. Even if didacticized information (rather of type C) can sometimes be called on, verbalized information (of type D) is largely dominant. The medium of the message is oral but it is also visual owing to session observations.

- Life in the high school, which constitutes an extension of collective life during the groups but that also here concerns all establishment personnel. These exchanges, very much marked by a convivial if not fraternal dimension, use only verbalized information, a little bit of type A, a lot of type B, and exclusively call on the mode of oral communication.

\section{- The "collaborative platform" device}

We will distinguish three modes:

- "Courses," collective contributions supplied by trainers and addressing a group. These involve didacticized information, rather of type $\mathrm{C}$ and using writing and audiovisual media.

- Logbooks, based on inter-individual exchanges in the frame of work to submit, corrections, or weekly activities. Here again, these involve didacticized information, rather of type $\mathrm{C}$ and using writing and audiovisual media.

- Forums that can include or exclude trainers and that constitute the virtual extension of collective life. These exchanges, strongly marked by a convivial if not fraternal dimension, use only verbalized information, a little bit of type A, a lot of type B, and exclusively call on the mode of writing. 
3.1.3 Summary: a typology of information inputs in the organization

\begin{tabular}{|c|c|c|c|c|c|c|}
\hline & & \begin{tabular}{|l|} 
Form of \\
diffusion
\end{tabular} & Addressee & Medium & $\begin{array}{l}\text { Knowledge } \\
\text { called on }\end{array}$ & $\begin{array}{l}\text { Informat- } \\
\text { ion }\end{array}$ \\
\hline \multirow[t]{3}{*}{ ENFA Groups } & $\begin{array}{l}\text { Training } \\
\text { sessions }\end{array}$ & $\begin{array}{l}\text { Formal- } \\
\text { ized }\end{array}$ & Collective & Oral & Type C or D & $\begin{array}{l}\text { Didactic- } \\
\text { ized }\end{array}$ \\
\hline & $\begin{array}{l}\text { Trainer / } \\
\text { trainee teacher } \\
\text { meetings }\end{array}$ & $\begin{array}{c}\text { Not very } \\
\text { formalized }\end{array}$ & Individual & Oral & Type B (or A) & Verbalized \\
\hline & $\begin{array}{l}\text { Exchanges } \\
\text { between trainee } \\
\text { teachers }\end{array}$ & $\begin{array}{c}\text { Not very } \\
\text { formalized }\end{array}$ & $\begin{array}{l}\text { Collective } \\
\text { Individual }\end{array}$ & Oral & Type B (or A) & Verbalized \\
\hline \multirow[t]{2}{*}{$\begin{array}{l}\text { Establishment- } \\
\text { based training }\end{array}$} & $\begin{array}{l}\text { Pedagogical } \\
\text { counselor }\end{array}$ & $\begin{array}{l}\text { Formal- } \\
\text { ized }\end{array}$ & Individual & $\begin{array}{c}\text { Oral } \\
\text { Visual }\end{array}$ & Type A & Verbalized \\
\hline & $\begin{array}{l}\text { Life in the high } \\
\text { school }\end{array}$ & $\begin{array}{c}\text { Not very } \\
\text { formalized }\end{array}$ & $\begin{array}{l}\text { Collective } \\
\text { Individual }\end{array}$ & Oral & Type B (or A) & Verbalized \\
\hline \multirow[t]{3}{*}{$\begin{array}{l}\text { The } \\
\text { collaborative } \\
\text { platform }\end{array}$} & Courses & $\begin{array}{l}\text { Formal- } \\
\text { ized }\end{array}$ & Collective & $\begin{array}{c}\text { Written } \\
\begin{array}{c}\text { Audiovis- } \\
\text { ual }\end{array}\end{array}$ & Type C & $\begin{array}{l}\text { Didactic- } \\
\text { ized }\end{array}$ \\
\hline & Logbook & $\begin{array}{l}\text { Formal- } \\
\text { ized }\end{array}$ & individual & $\begin{array}{c}\text { Written } \\
\text { Audiovis- } \\
\text { ual }\end{array}$ & Type C & $\begin{array}{l}\text { Didactic- } \\
\text { ized }\end{array}$ \\
\hline & Forums & $\begin{array}{c}\text { Not very } \\
\text { formalized }\end{array}$ & $\begin{array}{l}\text { Collective } \\
\text { Individual }\end{array}$ & Written & Type B (or A) & Verbalized \\
\hline
\end{tabular}

\section{2 - The various modes of sharing and their effects}

\subsection{1 - The "ENFA Groups" device}

We have chosen three modes of information diffusion, discussed early in the presentation of inputs: course sessions, trainer / trainee teacher exchanges outside of these sessions, and exchanges between trainee teachers in moments of community life (breaks, meals, evening activities, etc.). As the following table indicates, this sharing is largely identified by the trainee teachers (creation of trainee teacher / trainer links) and we observe the elaboration of knowledge relative to both professional socialization (they strongly emphasize the contribution of these groups to the creation of a "cohort" of trainee teachers) and the undertaking of professional tasks (answers, solutions, confidence for practicing the profession).

Opinions of trainee teachers on the objectives and functions of the groups

They enable the creation of links between trainers and trainee teachers $100 \%$

They enable the creation of links between the pedagogical counselor, the trainers, $59.5 \%$ and the trainee teachers

They allow you to find answers to your questions $59.5 \%$

They allow you to gain confidence regarding complex situations 
It should be mentioned that in terms of contributions, the groups and hence the modes of knowledge sharing that they permit are judged to be "useful" to professionalization (in both the short and the medium term).

Trainee teachers' opinions on the contributions of the two groups, G1 and G2

\begin{tabular}{|l|c|c|c|c|c|}
\hline & Interesting & Effective & Useful immediately & Useful later & Not useful \\
\hline G1 & $16.5 \%$ & $9.5 \%$ & $32.4 \%$ & $25.6 \%$ & $16 \%$ \\
\hline G2 & $19.7 \%$ & $10.8 \%$ & $28.9 \%$ & $22.9 \%$ & $17.9 \%$ \\
\hline
\end{tabular}

\subsection{2 - The "establishment-based training" device}

At the establishment level, interactions with pedagogical counselors are rather frequent:

Frequency of exchanges between trainee teachers and pedagogical counselors (according to

$$
\text { group) }
$$

\begin{tabular}{|l|c|c|c|}
\hline & Very often or often & Occasional & Never \\
\hline Before G1 & $84.67 \%$ & $16.22 \%$ & $8.11 \%$ \\
\hline Between G1 and G2 & $89.19 \%$ & $10.81 \%$ & $0.00 \%$ \\
\hline After G2 & $81.08 \%$ & $18.92 \%$ & $0.00 \%$ \\
\hline
\end{tabular}

This interaction mostly takes the form of a face-to-face meeting and it can be observed that even if the work of analysis is foremost based on the practices of the trainee teacher, this trainee will very regularly observe the work of the pedagogical counselor:

Modes of exchanges between trainee teachers and pedagogical counselors (according to group)

\begin{tabular}{|l|c|}
\hline Visit by the pedagogical counselor (with observation of the trainee teacher's class) & $94.59 \%$ \\
\hline Visit by the trainee teacher (with observation of the pedagogical counselor's class) & $72.97 \%$ \\
\hline Mail & $67.57 \%$ \\
\hline $\begin{array}{l}\text { Visit by the trainee teacher (without observation of the pedagogical counselor's } \\
\text { class) }\end{array}$ & $54.05 \%$ \\
\hline $\begin{array}{l}\text { Telephone } \\
\text { Visit by the pedagogical counselor (without observation of the trainee teacher's }\end{array}$ & $48.65 \%$ \\
\hline class) & $48.65 \%$ \\
\hline Moodle platform & $10.81 \%$ \\
\hline
\end{tabular}

Finally, as with the ENFA Groups device, the contribution of pedagogical counselors to their professionalization is recognized by the trainee teachers:

Assessment of the effects of pedagogical counselors' actions on the professional mastery of trainee teachers (rate of agreement with statements)

\begin{tabular}{|l|r|}
\hline You would not have succeeded in becoming integrated into a team & $81 \%$ \\
\hline You would not have succeeded in managing a class & $77.5 \%$ \\
\hline You would not have participated in pedagogical or educational projects & $55.7 \%$ \\
\hline You would not have succeeded in progressing in your teaching & $54 \%$ \\
\hline You think you would have lost a great deal of time & $27 \%$ \\
\hline
\end{tabular}

\subsection{3 - The "collaborative platform" device}

In contrast with the previous devices, the collaborative platform is based on virtual exchanges, hence "the knowledge management infrastructure will have a much greater chance of providing significant long-term value to the organization" (Zack, 1999). 
Generally speaking, the use of a platform by trainee teachers is important even if the frequency of its use stabilizes after the first group (G1):

Frequency of use of Moodle platform by trainee teachers (according to group)

\begin{tabular}{|l|c|c|c|}
\hline & Often or Very often & Occasional & Never \\
\hline Before G1 & $27 \%$ & $37.84 \%$ & $35.14 \%$ \\
\hline Between G1 and G2 & $51.3 \%$ & $45.95 \%$ & $2.70 \%$ \\
\hline After G2 & $13.51 \%$ & $70.27 \%$ & $16.22 \%$ \\
\hline
\end{tabular}

The diversity of addressees of submitted work is an indicator of the richness of exchanges:

Frequency of work sent by the trainee teachers on the Moodle platform

\begin{tabular}{|l|c|c|c|}
\hline & Before G1 & Between G1 and G2 & After G2 \\
\hline Trainers & $40.5 \%$ & $71.9 \%$ & $72.2 \%$ \\
\hline Pedagogical counselor & $19 \%$ & $19 \%$ & $16.2 \%$ \\
\hline Other trainee teachers & $32.4 \%$ & $73 \%$ & $51.4 \%$ \\
\hline
\end{tabular}

We observe the strong interactivity of the platform, even if ENFA trainers interact much more with trainee teachers than pedagogical counselors, which is logical considering the geographical proximity of the latter:

Frequency of exchanges of the trainee teachers on the Moodle platform

\begin{tabular}{|l|c|c|c|}
\hline & Before G1 & Between G1 and G2 & After G2 \\
\hline Trainers & $59.4 \%$ & $97.3 \%$ & $78.4 \%$ \\
\hline Pedagogical counselor & $65 \%$ & $67.6 \%$ & $67.6 \%$ \\
\hline
\end{tabular}

\section{$\underline{\text { Appreciation of "distance monitoring" by trainee teachers }}$}

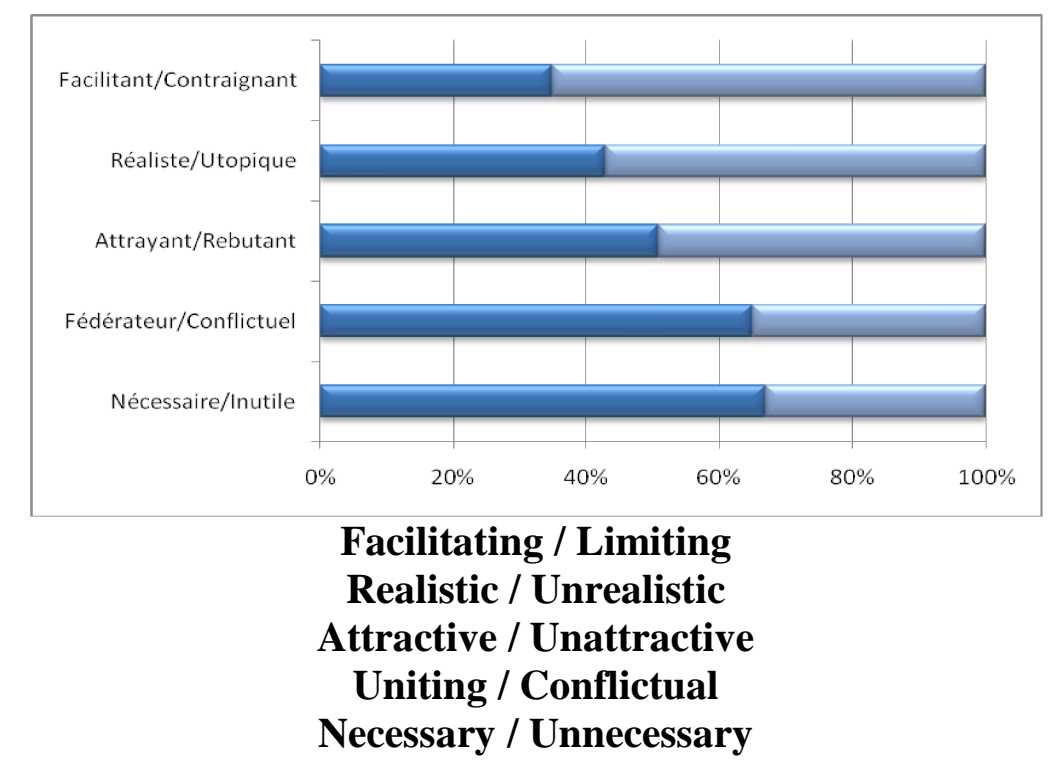

\section{3 - Products of the organization: an overview of converted knowledge}

These products are here considered only as concerns trainee teachers, since their professionalization constitutes the primary objective of this device. It can nevertheless be considered that knowledge conversion processes enabled by this organization also had effects on ENFA trainers and pedagogical counselors. 


\subsection{1 - On knowledge related to professional socialization}

We first chose activity on the various forums of the platform as an indicator of a professional "sociality," that is, a degree of integration within a professional community. This activity is important even if it largely favors consultation rather than expression (message):

$\underline{\text { Forum activities }}$

\begin{tabular}{|c|c|c|c|}
\hline \multirow{2}{*}{$\begin{array}{c}\text { "Weekly activities" } \\
\text { forum }\end{array}$} & Trainee teachers & Consultations & Messages \\
\cline { 2 - 4 } & $\begin{array}{c}\text { Trainers and pedagogical } \\
\text { counselors }\end{array}$ & 5206 & 444 \\
\hline "Individualized & Trainee teachers & 2275 & 141 \\
\hline trainings" forum & ENFA trainers & 2098 & 12 \\
\hline
\end{tabular}

With regard to "professional socialization," we have already signaled the importance of the ENFA Groups in the constitution of a "cohort of trainee teachers" and hence the beginning of a sense of belonging to a professional body (in line with professional identity).

Finally, in the establishment, the themes addressed during the integration phase contribute to the development of a true "professional culture" as shown in the following table:

Frequency and themes of exchanges between trainee teachers and administration members while assuming a position in the establishment

\begin{tabular}{|l|l|}
\hline Students & $78.4 \%$ \\
\hline Pedagogical means attributed & $59.5 \%$ \\
\hline New responsibilities & $54.1 \%$ \\
\hline Work time & $48.7 \%$ \\
\hline Positioning with regard to other colleagues & $43.3 \%$ \\
\hline Salary & $43.3 \%$ \\
\hline Parents of students & $43.3 \%$ \\
\hline Hierarchy & $43.3 \%$ \\
\hline Institutional recognition & $24.4 \%$ \\
\hline
\end{tabular}

\section{Knowledge relative to undertaking professional tasks}

\section{An evaluation based on a Sense of Professional Efficacy}

The evaluation of organizational products is based on the notion of the Sense of Personal SelfEfficacy, defined by Bandura as follows: "The perception of personal efficacy concerns the individual's belief in his/her ability to organize and execute the line of conduct required to produce desired outcomes" (Bandura, 2003). This personal efficacy results from selfevaluation and the title of Bandura's book is in fact Self-Efficacy. Based on a review of the Sense of Personal Efficacy, Galand and Vanlede (2004) underscore the convergence of results showing "the existence of a relation between the sense of personal efficacy and performance or perseverance" (p. 6.) and maintaining that "the performance of learners depends not only on their 'objective' competencies but also on their confidence in their mastery of these competencies" (p. 7). Once again, a link is drawn between professional action and professional practice, which constitutes the objective of the "professionalization year" device here studied.

In this paper, the sphere explored being the professional sphere, we will discuss the Sense of Professional Efficacy (SPE), which is simply a sub-set of the previously mentioned one. 
The sense of mastery of teaching tasks

Among the professional tasks, we will first examine teaching-related tasks:

Select the contents to teach in a session and organize their presentation

Elaborate a progression over the year or part of the year

Choose student activities and assess their related difficulties

Plan the pedagogical structure of the session (management, group work)

Manage the pedagogical relationship

\section{Identify and address student difficulties}

Identify inappropriate behavior and maintain order

Evaluate students

Manage classroom space and movements (posture, gestures, positioning)

Identify and analyze student difficulties, and plan remedial measures
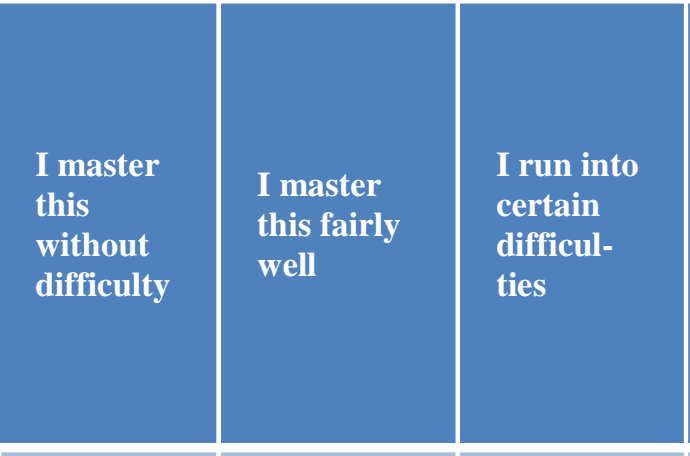

I run into

many

difficul-

ties

\begin{tabular}{|l|l|l|l|}
\hline $8.11 \%$ & $64.86 \%$ & $27.03 \%$ & \\
\hline $8.11 \%$ & $64.86 \%$ & $24.32 \%$ & $2.70 \%$ \\
\hline $2.70 \%$ & $64.86 \%$ & $29.73 \%$ & $2.70 \%$ \\
\hline $13.51 \%$ & $67.57 \%$ & $16.22 \%$ & $2.70 \%$ \\
\hline $10.81 \%$ & $75.68 \%$ & $13.51 \%$ & \\
\hline $5.41 \%$ & $59.46 \%$ & $29.73 \%$ & $5.41 \%$ \\
\hline $8.11 \%$ & $51.35 \%$ & $37.84 \%$ & $2.70 \%$ \\
\hline $10.81 \%$ & $72.97 \%$ & $13.51 \%$ & $2.70 \%$ \\
\hline $21.62 \%$ & $70.27 \%$ & & $8.11 \%$ \\
\hline $8.11 \%$ & $62.16 \%$ & $27.03 \%$ & $2.70 \%$ \\
\hline
\end{tabular}

We can see that the right level of mastery is asserted by trainee teachers, considering that for the year of studies surveyed, "I master fairly well" corresponds to an acceptable degree.

\section{The sense of mastery of other teaching tasks}

It can be seen that the sense of mastery is a little weaker for the other professional tasks involving modes of collaboration or partnership:

\section{$\underline{\text { Collaborations or partnerships }}$}

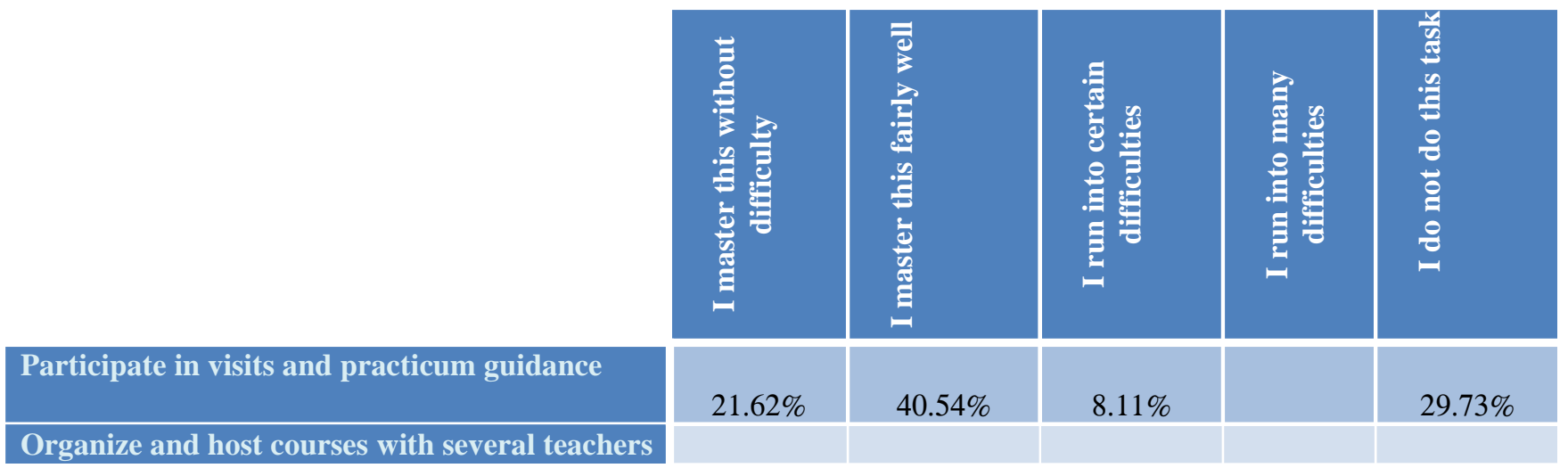




\begin{tabular}{|l|c|c|c|c|c|}
\hline $\begin{array}{l}\text { (tutored personal work, pluridisciplinary } \\
\text { module) }\end{array}$ & $16.22 \%$ & $51.35 \%$ & $16.22 \%$ & $5.41 \%$ & $10.81 \%$ \\
\hline $\begin{array}{l}\text { Participate in developing tests, examination } \\
\text { planning, evaluation over the year }\end{array}$ & $5.41 \%$ & $59.46 \%$ & $21.62 \%$ & $8.11 \%$ & $5.41 \%$ \\
\hline $\begin{array}{l}\text { Participate in pedagogical and educational } \\
\text { projects }\end{array}$ & $16.22 \%$ & $40.54 \%$ & $35.14 \%$ & $8.11 \%$ \\
\hline $\begin{array}{l}\text { Exchange information on the students or the } \\
\text { conduct of the class (teacher's room, cafeteria) }\end{array}$ & $35.14 \%$ & $56.76 \%$ & $8.11 \%$ & & \\
\hline $\begin{array}{l}\text { Participate in establishment structures (e.g. the } \\
\text { board of directors) }\end{array}$ & $10.81 \%$ & $16.22 \%$ & $13.51 \%$ & $5.41 \%$ & $54.05 \%$ \\
\hline $\begin{array}{l}\text { Establish relationships with outside partners } \\
\text { (parents of students; professionals; institutional } \\
\text { and associated partners) }\end{array}$ & $10.81 \%$ & $48.65 \%$ & $24.32 \%$ & $2.70 \%$ & $13.51 \%$ \\
\hline
\end{tabular}

\section{4 - Initial modeling of organizational knowledge conversion}

This first portion of the study enabled an exploration of the space of knowledge conversion (modes of sharing within the organization) in line with:

- the inputs, the information diffused within the various devices (before its conversion);

- the outputs, the professional knowledge of trainee teachers (after its conversion).

The results permitted us to sketch out the following model:

\begin{tabular}{|c|c|c|c|c|c|}
\hline \multicolumn{2}{|c|}{ Inputs into the organization } & \multicolumn{2}{|c|}{$\begin{array}{l}\text { Conversion space: } \\
\text { modes of sharing within the organization }\end{array}$} & \multicolumn{2}{|c|}{ Products of the organization } \\
\hline \multirow{5}{*}{$\begin{array}{l}\text { Information } \\
\text { relative to } \\
\text { undertaking } \\
\text { professional tasks }\end{array}$} & \multirow[t]{4}{*}{ Tacit } & \multirow[t]{3}{*}{ ENFA Groups } & Information sessions & \multirow{5}{*}{$\begin{array}{l}\text { Knowledge } \\
\text { relative to } \\
\text { undertaking } \\
\text { professional } \\
\text { tasks }\end{array}$} & \multirow[t]{4}{*}{ Teaching tasks } \\
\hline & & & $\begin{array}{l}\text { Trainer / Trainee teacher } \\
\text { meetings }\end{array}$ & & \\
\hline & & & $\begin{array}{l}\text { Exchanges between trainee } \\
\text { teachers }\end{array}$ & & \\
\hline & & \multirow{2}{*}{$\begin{array}{l}\text { Establishment-based } \\
\text { training }\end{array}$} & Pedagogical counselor & & \\
\hline & Explicit & & Life in the high school & & $\begin{array}{l}\text { Other } \\
\text { professional } \\
\text { tasks } \\
\text { (collaboration, } \\
\text { partnership) }\end{array}$ \\
\hline \multirow{4}{*}{$\begin{array}{l}\text { Information } \\
\text { relative to } \\
\text { undertaking } \\
\text { professional } \\
\text { socialization }\end{array}$} & Tacit & \multirow{4}{*}{$\begin{array}{l}\text { The collaborative } \\
\text { platform }\end{array}$} & Courses & \multirow{4}{*}{$\begin{array}{l}\text { Knowledge } \\
\text { relative to } \\
\text { undertaking } \\
\text { professional } \\
\text { socialization }\end{array}$} & \multirow{2}{*}{$\begin{array}{l}\text { Professional } \\
\text { socialization }\end{array}$} \\
\hline & \multirow[t]{3}{*}{ Explicit } & & Logbook & & \\
\hline & & & Forums & & $\begin{array}{l}\text { Professional } \\
\text { identity }\end{array}$ \\
\hline & & & & & $\begin{array}{l}\text { Professional } \\
\text { culture }\end{array}$ \\
\hline
\end{tabular}

\section{4 - Analysis of processes}

We supplemented the information input / dynamics of knowledge conversion / results approach with an analysis of the four processes proposed by Nonaka. As we will see, these processes certainly mobilize the epistemological (relative to the nature of knowledge) and ontological (relative to the knower) dimensions, but seem to be highly sensitive to the influence of a third dimension, that of action and social practices, which we have labeled as praxeological.

\section{1 - Socialization}


In regard to the epistemological dimension, the tacit knowledge converted principally covers collective work and "professional norms" (Van Zanten, 2001) :

\begin{tabular}{|c|c|c|c|c|}
\hline $\begin{array}{l}\text { When you had the opportunity to collaborate with } \\
\text { colleagues in the frame of various projects, would you say } \\
\text { that you gradually felt more comfortable: }\end{array}$ & Not really & $\begin{array}{l}\text { Slightly } \\
\text { more }\end{array}$ & $\begin{array}{c}\text { More and } \\
\text { more }\end{array}$ & Completely \\
\hline With respect to the distribution of tasks within the group & $7.89 \%$ & $23.68 \%$ & $52.63 \%$ & $15.79 \%$ \\
\hline With respect to the way to work & $7.89 \%$ & $10.53 \%$ & $60.53 \%$ & $21.05 \%$ \\
\hline With respect to the functioning of the group & $7.89 \%$ & $13.16 \%$ & $57.89 \%$ & $21.05 \%$ \\
\hline $\begin{array}{l}\text { With respect to the references mobilized (students, } \\
\text { frameworks, context, etc.) }\end{array}$ & $10.53 \%$ & $13.16 \%$ & $60.53 \%$ & $15.79 \%$ \\
\hline With respect to the vocabulary used & $10.53 \%$ & $13.16 \%$ & $52.63 \%$ & $23.68 \%$ \\
\hline
\end{tabular}

When it comes to the ontological dimension, there are dual or collective categories of "knowers":

When you had the opportunity to collaborate with colleagues in the frame of various projects, would you say that you gradually felt more comfortable:

\begin{tabular}{|c|c|c|c|c|}
\hline When speaking to colleagues in the teacher's room & $15.79 \%$ & $18.42 \%$ & $34.21 \%$ & $31.58 \%$ \\
\hline When discussing with colleagues at the school cafeteria & $28.95 \%$ & $28.95 \%$ & $28.95 \%$ & $13.16 \%$ \\
\hline \begin{tabular}{|lllll}
$\begin{array}{l}\text { When informally exchanging with your tutor or } \\
\text { pedagogical counselor }\end{array}$ & & \\
\end{tabular} & $5.26 \%$ & $15.79 \%$ & $31.58 \%$ & $47.37 \%$ \\
\hline When exchanging on Moodle with other trainee teachers & $60.53 \%$ & $26.32 \%$ & $10.53 \%$ & $2.63 \%$ \\
\hline When exchanging on forums with ENFA trainers & $44.74 \%$ & $36.84 \%$ & $13.16 \%$ & $5.26 \%$ \\
\hline
\end{tabular}

These results point to the substantial difference of a physical visit as opposed to a virtual exchange. These verbal exchanges hint at the emergence of a praxeological dimension in which "speaking together" would extend to "doing together."

\section{2 - Externalization}

Based on the question presented in the first box and by synthesizing the results (in terms of both the nature of knowledge and the modes of sharing within each device), the following table is arrived at:

\begin{tabular}{|l|c|c|c|}
\hline $\begin{array}{l}\text { During the first months of experience, would you say } \\
\text { that a certain amount of professional knowledge (or } \\
\text { ways of doing things) that you use in your work was } \\
\text { formalized explicitly, whether in writing or in oral } \\
\text { communication (procedures, work rules, } \text { etc.)? Could } \\
\text { you discuss the following categories of knowledge and } \\
\text { the spaces where they were formalized: }\end{array}$ & $\begin{array}{c}\text { During ENFA } \\
\text { Groups }\end{array}$ & $\begin{array}{c}\text { In the } \\
\text { establish- } \\
\text { ment }\end{array}$ & $\begin{array}{c}\text { On the } \\
\text { collaborative } \\
\text { platform }\end{array}$ \\
\hline Knowledge relative to managing or evaluating students & ++ & ++++ & -- \\
\hline $\begin{array}{l}\text { Knowledge relative to the organization of and } \\
\text { pedagogical materials for a given session }\end{array}$ & +++ & ++++ & - \\
\hline Knowledge relative to the content to teach & ++++ & ++++ & + \\
\hline Knowledge relative to collaborations with teachers or & ++ & +++ & - \\
\hline
\end{tabular}




\begin{tabular}{|l|c|c|c|}
\hline the functioning of pedagogical teams & & & \\
\hline Knowledge relative to the various partnerships & + & +++ & - \\
\hline
\end{tabular}

In general we observe that the externalization process varies according to the epistemological dimension (nature of knowledge) and the epistemic dimension (the knower concerned). On this subject a clear difference can be seen with regard to physical exchange as opposed to virtual exchanges on the platform. A difference can also be observed between ENFA Groups (which favor verbal exchanges) and establishment-based training that reinforces the link with professional practice, shared practice, and thus a praxeological dimension.

\section{3 - Combination}

To explore the combination process, that is, a conversion of explicit knowledge toward a greater level of explicitation, we can observe that this process concerns knowledge for teaching and the knowledge to teach more extensively than knowledge relative to collaborations or partnerships:

Would you say that the formalization of this different knowledge (or ways of doing things) and its organization within larger systems (sets of procedures, rules, specification books, instruction manuals, etc.) has generated and formalized new professional knowledge (or ways of doing things) as concerns the following areas:

\begin{tabular}{|c|c|c|c|c|}
\hline & & & & \\
\hline & $23.68 \%$ & $31.58 \%$ & $36.84 \%$ & $7.89 \%$ \\
\hline $\begin{array}{l}\text { Knowledge relative to the organization of and pedagogical } \\
\text { materials for a given session }\end{array}$ & $\begin{array}{c}7 \\
18.42 \%\end{array}$ & $\begin{array}{c}15 \\
39.47 \%\end{array}$ & $\begin{array}{c}13 \\
34.21 \%\end{array}$ & $\begin{array}{c}3 \\
7.89 \%\end{array}$ \\
\hline Knowledge relative to the content to teach & 23. & $26.32 \%$ & $42.11 \%$ & $7.89 \%$ \\
\hline $\begin{array}{l}\text { Knowledge relative to collaborations with teachers or the } \\
\text { functioning of pedagogical teams }\end{array}$ & $21.05 \%$ & $44.74 \%$ & $26.32 \%$ & $7.89 \%$ \\
\hline Knowledge relative to the various partnerships & $28.95 \%$ & $50.00 \%$ & $21.05 \%$ & \\
\hline $\begin{array}{l}\text { Knowledge relative to undertaking tasks specific to ESC [so } \\
\text { cultural education] teachers and documentalist teachers }\end{array}$ & $42.11 \%$ & $39.47 \%$ & $13.16 \%$ & $5.26 \%$ \\
\hline
\end{tabular}

\section{4 - Internalization}

By adopting the same method as for the externalization process, the following table is obtained for the internalization process:

\begin{tabular}{|l|c|c|c|}
\hline $\begin{array}{l}\text { Among the various resources at your disposal for } \\
\text { your work that have been formalized during these } \\
\text { months of experience (in the establishment, during } \\
\text { groups, or over the course of distance } \\
\text { monitoring), could you specify the facility with } \\
\text { which you have mobilized: }\end{array}$ & $\begin{array}{c}\text { During ENFA } \\
\text { Groups }\end{array}$ & $\begin{array}{c}\text { In the } \\
\text { establish- } \\
\text { ment }\end{array}$ & $\begin{array}{c}\text { Through } \\
\text { distance } \\
\text { monitoring }\end{array}$ \\
\hline $\begin{array}{l}\text { Knowledge relative to managing or evaluating students } \\
\text { Resources relative to the organization of and } \\
\text { pedagogical materials for a session }\end{array}$ & ++ & +++ & ++ \\
\hline $\begin{array}{l}\text { Resources relative to the content to teach } \\
\text { Resources relative to collaborations with teachers or the } \\
\text { functioning of pedagogical teams }\end{array}$ & ++ & ++ & + \\
\hline Knowledge relative to the various partnerships & ++ & ++ & + \\
\hline
\end{tabular}


In general we observe that the internalization process varies fairly little according to the epistemological dimension (nature of explicit knowledge, here resources) and much more according to the epistemic dimension (the knower concerned). In this regard a clear difference can be noted according to whether these resources were developed through physical exchanges or virtual exchanges over the course of distance monitoring. A difference can also be observed between resources developed over the course of ENFA Groups (principally based on verbal exchanges) and establishment-based training that reinforces the link with professional practice, shared practice, and thus a praxeological dimension.

\section{5- Discussion on the contribution to the modeling of organizational knowledge conversion}

The contributions of our study permit us to re-question the Nonaka model and to suggest, in conclusion, a few avenues for further development.

\section{1 - On the praxeological dimension}

We have just seen that the four processes advanced by Nonaka fully make use of the epistemological (relative to the nature of knowledge) and ontological (relative to the knower) dimensions, but there clearly emerges the importance of a third dimension that we have described as praxeological (relative to social practices).

First, the linking of the epistemological and ontological dimensions cannot be done without taking into account a "meeting," regardless of the type of knower. Of course, this meeting can be virtual, for example by means of a collaborative platform, as we have seen. But physical meeting is unmistakably identified by respondents as a far superior contributor to the process of knowledge conversion. Here again, however, there is a distinction to be made concerning the space in which the meeting takes place: meetings within a space of training (ENFA) appear to be less "effective" than meetings within a space of work (the establishment). If we establish a gradation between the three devices from the weakest contributor to the knowledge conversion process to the strongest, we find a correlation with the importance of the action, an action that is in no way isolated but that takes the form, under the designation of social practice, of various modes of collaboration, cooperation, partnership, or teamwork.

This relates to an extensive portion of our research devoted to the work of teachers with the notion of "shared work" (Marcel et al., 2009) showing that the sharing of professional action sets up a social dynamic that generates professional development. It can therefore be said that the praxeological dimension (understood as the dimension of social practices and shared action) complements the two previous ones; by involving the intervention of an "other," this dimension enables articulation of the epistemological and ontological dimensions. But this other acts with the subject through a social dynamic that transforms the subject and provides an additional impetus to the conversion of knowledge.

We would like to add a sort of analogy that can easily be found between knowledge conversion processes at work in the studied organization and the conversion processes required for professional practice. It simply appears that the hierarchies in the contributing dimensions are slightly different: during the professionalization year, the epistemological dimension comes first; during integration into the profession, it is the praxeological dimension that is stressed; but in each case the contribution of the three dimensions is preserved. Knowing and acting appear to be branches of the same tree.

\section{2 - The need to take contexts into account}


The consideration of a praxeological dimension raises the question of the situation or broader context, which will result in a complexification of the three axes:

- The praxeological axis will become enriched by integrating the context of action in its various dimensions; among these, we will limit ourselves to mentioning spatial, temporal, material, institutional, and symbolic dimensions.

- The epistemological axis will need to take into account the contexts of knowledge. We will cite two: the first directly relating to the studied case and concerning the finalization of knowledge by the organization (here, preparation for a profession); and the second relative to the social-historical-cultural anchoring of knowledge in a given era, what Khun names paradigms, and that give a "form" and are specific to the knowledge diffused within the organization.

- The ontological axis will have to become complexified through the contexts of subjects (whether individual or collective) and in this regard we will cite the importance of the biographical, cultural, and axiological spheres.

\section{3 - On the complexification of the Nonaka spiral}

Our contribution thus lies in proposing a complexification of the Nonaka spiral on two levels. First, by adding a third axis, the one corresponding to the praxeological dimension of conversion processes, then by complexifying each of the three axis with their various contexts. Perhaps a fourth process could be considered, hinted at in the previously mentioned ones and related to the memory of the organization. This memorization process is often likened to that of capitalisation or accumulation, which, owing to its static side, would be in contradiction with the continuum characterizing the conversion process. We suggest a different way of thinking: the continuum between subjectivity and objectivity (favored by the social practices of shared action) can, by analogy with the third world of Popper, also consider knowledge susceptible to be freed from the conditions in which it was elaborated. As a result the conversion process would become complexified by a memorization process (which is in fact nothing other than a particular form of conversion). On the other hand, at the output of the organization, converted knowledge would remain strongly tied to the specific case of the organization that allowed its conversion, while memorized knowledge would have a much higher degree of generalization. Another element of Nonaka's model remains to be questioned, namely its spiral motion. It seems interesting to us to make a parallel between this model and the proposed model, in an entirely different context, by way of Vygotsky and child development. Just one element of this model worthy of note is the zone of proximal development that corresponds to the cognitive area of tasks the child is capable of realizing with the mediation of the adult, but cannot yet carry out alone. In the Vygotskian spiral, there is the idea of reiteration: a child learns twice-once with an adult, once alone. We could establish a relation between this reflection and two elements of the model: the ontological axis (with the various knowers and their interdependencies) on the one hand and the praxeological axis, in connection with action and its iterations, on the other. Finally, the spiral form brings about the question of temporality. A continuum in a sense refers to the arrow of time, that is, irreversible time polarized by the future; a spiral instead refers to a cyclical time expressing the immediacy of the present (in line with the action/situation pair) and the ballasting of the past (in line with reiteration). With respect to the study of the conversion process, we maintain the necessity of considering a systemic time, that is, one that articulates, in a projection of the future, the instantaneity of the present as well as the weight of the past. 


\section{planes}

\section{4 - Rethinking the components of the organization in context: from axes to}

In summary, we would like to advance a perspective whose heuristic potentiality will not have been sufficiently developed in this text but that brings up questions for future research. The emergence of a third axis establishes planes in the model, at least geometrically speaking. As a result, it is interesting to consider the conversion process with regard to the relation of each of the planes with the "absent third," the third axis. Hence we have:

- a knowledge (epistemological axis), embodied and mobilized (onto-praxeological plane), that brings to the conversion process a touch of irreducible unpredictability (that of action in context) and that brings it closer to the problems of change;

- an action (praxeological axis), embodied and enlightened (onto-epistemological plane), that frees the conversion process from reflexivity (dear to Schön and Argyris) and which, following neo-Piagetians, underlines the development of knowledge in and through action; and

- a knower (ontological axis), knowing and acting (epistemo-praxeological axis), that constrains the conversion process to take into account the question of the responsibility of the knower, whether a moral or legal entity.

Further exploration of each of the four processes is certainly warranted, but we will reserve this analysis for a later time.

\section{Bibliography}

BANDURA, A. (2003). Auto-efficacité. Le sentiment d'efficacité personnelle. Bruxelles : De Boeck.

BAUMARD, Philippe (1996). Organisations déconcertées : la gestion stratégique de la knowledge. Paris : Masson, Chapitre 1 : La knowledge dans les organisations. PP. 7-21

COUZINET, Viviane (2008). les dispositifs info-communicationnels. Paris : Editions Hermès.

DELEUZE, Guy (1986). Le monde, 5 juin 1986, p. 13

FOUCAULT, Michel (1975). L'archéologie du savoir. Paris : Gallimard, 275 p.

GALAND, B. \& VANDELE, M. (2004). Le sentiment d'efficacité personnelle dans l'apprentissage et la formation. Quel rôle joue-t-il ? D’où vient-il ? Comment intervenir ? Les Cahiers de Recherche en Education et Formation, 29.

HERT, Philippe (1999). Internet comme dispositif hétérotopique. Hermès, ${ }^{\circ}$ 25, p. 93-110.

LOSFELD, Gérard (1990). Sciences de l'information VS sciences de la communication : éléments pour un dialogue épistémologique. In ACTES DU CONGRES INFORCOM 90 (Société française des sciences de l'information et de la communication) (24-26 mai 1990 ; La Baume les Aix). La recherche en informationcommunication : l'avenir. Aix en Provence : Université de Provence. Pp. 161-166.

MARCEL, J-F. (2009) De la prise en compte des pratiques enseignantes de travail partagé, Les Nouveaux Cahiers de la Recherche en Education, Vol. 12, nº1, p. 47-64, http://ncre.educ.usherbrooke.ca/page.php? $\underline{\text { rep}}=$ catalogue \&page $=$ article $\&$ req $=$ details\&index $=223$

MEYRIAT, Jean (1983). - De la science de l'information aux métiers de l'information. - Schéma et schématisation, $\mathrm{n}^{\circ} 19$, p. $65-74$

NONAKA, IKUJIRO (1994). A dynamic Theory of organizational Knowledge Creation. Organization science, vol.5, $\mathrm{n}^{\circ} 1$, février, pp.14-37

NONAKA, IKUJIRO and PELTOKORPI, Vesa ( 2006). Objectivity and subjectivity in knowledge management : a review of 20 top articles. Knowledge and process management, vol 13, N², pp 73-82.

NONAKA, IKUJIRO, KROGH, VON GEORG (2009), Tacit knowledge and knowledge conversion : controversy and Advancement in organizational knowledge creation theory. Organization science, vol 20, $\mathrm{n}^{\circ} 3$, may-june 2009 PP 635-652.

OSTY, F. (2003). Le désir de métier. Engagement, identité et reknowledge au travail. Rennes, PUR. VAN ZANTEN, A. (2001). L'école de la périphérie. Scolarité et ségrégation en banlieue. PUF : Paris. ZACK, M. H. Developing a Knowledge Strategy California Management Review, Vol. 41, No. 3, Spring, 1999 , pp. $125-145$ 